\title{
Infiltrating lipoma of neck
}

\author{
Abhishek Vijayakumar, Vijayraj Patil, Avinash Vijayakumar
}

\section{To the Editor}

Lipomas are common benign soft tissue neoplasms of mature adipose tissue. The peak incidence is usually in the fifth or sixth decade of life, while occurrence in children is very uncommo. Multiple presentations may occur in about 5\% patients [1]. The tumors may or encapsulated may not be. In a review of more than 1000 benign tumors of adipose tissue, over $80 \%$ were ordinary lipomas; nearly all the others were angiolipomas, intramuscular lipomas, or lipoblastomas. Other types accounted for less than $2 \%$ of all benign lipomatous neoplasms [2]. The occurrence in the head and neck is relatively rare [3]. Only 25\% lipomas arise from the head and neck. Lipomas of the anterior neck are extremely rare. They may extend posteriomedially between the sternocleidomastoid and digastric muscles. Most commonly, they arise at the posterior subcutaneous neck [4]. The deep lipoma is usually larger and deforms the surrounding tissue as compared to superficial lipomas which are generally more circumscribed.

The subfascial or deep lipomas can be classified as parosteal, interosseous or visceral; and as intermuscular or intramuscular. Deep lipomas that are either intermuscular or intramuscular have been described as infiltrating lipomas by Terziogluet et al. [5] Lipomas are typically asymptomatic unless they compress

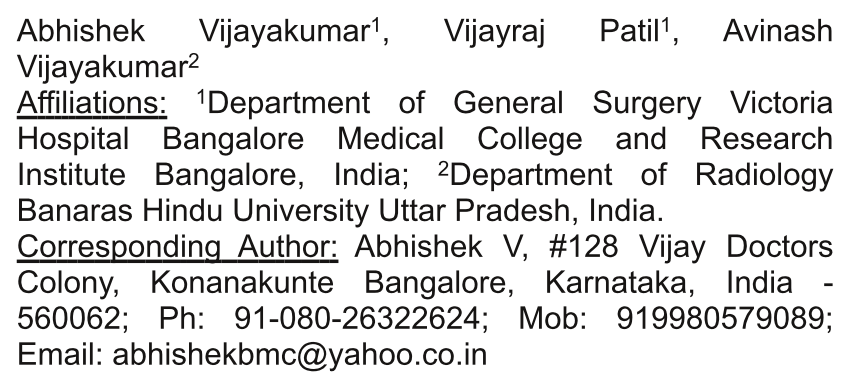

Received: 06 August 2012

Accepted: 17 October 2012

Published: 01 May 2013 neurovascular structures. The deep lipoma often present without clinical symptoms and therefore grow to a large size before they are detected.

Intermuscular lipomas are rare, with an incidence of 1.8\%. After complete resection, there is a $19 \%$ recurrence rate of intramuscular lipomas. Surgical intervention is challenging because of the proximity of the blood vessels and the nerves and thus the knowledge of anatomy and meticulous surgical technique are essential.

We report a rare case of infiltrating lipoma of the neck in a young male. A 20-year-old male presented with swelling in the neck since six months which was painless and gradually increasing in size. Clinical examination revealed a soft swellling in anterolateral aspect of the neck extending behind the clavicle. A probable diagnosis of cystic hygroma was made.

A computer tomography (CT) scan of neck and thorax was performed before and after administration of intravenous contrast material. Sagittal and coronal images demostrated a homogenous lobulated lesion extending superiorly from the angle of mandible to sternal angle inferiorly (Figures 1-3). Medio-laterally it extended from just across the midline into the posterior neck and also extending anterior to subscapularis. It was extending inferiorly into the axilla and upper arm

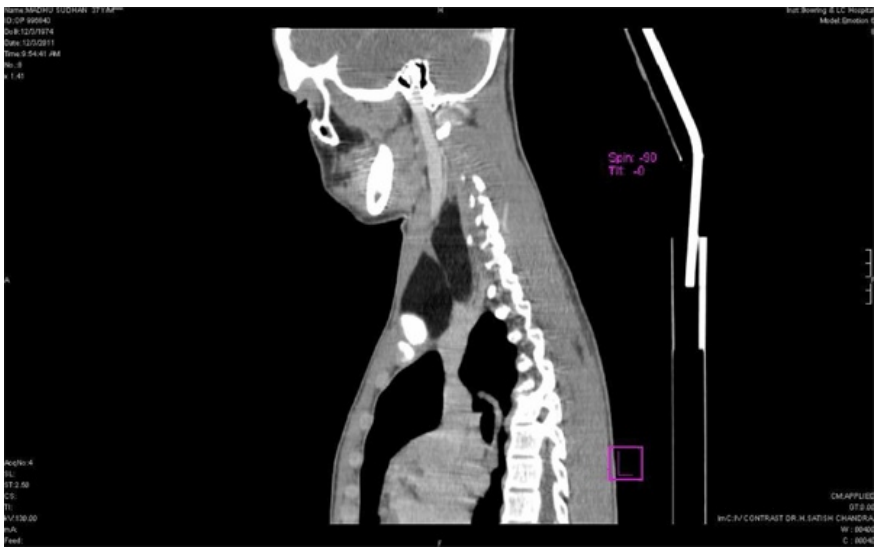

Figure 1: Computed tomography (CT) scan showing anteroposterior extent of infiltrating lipoma. 


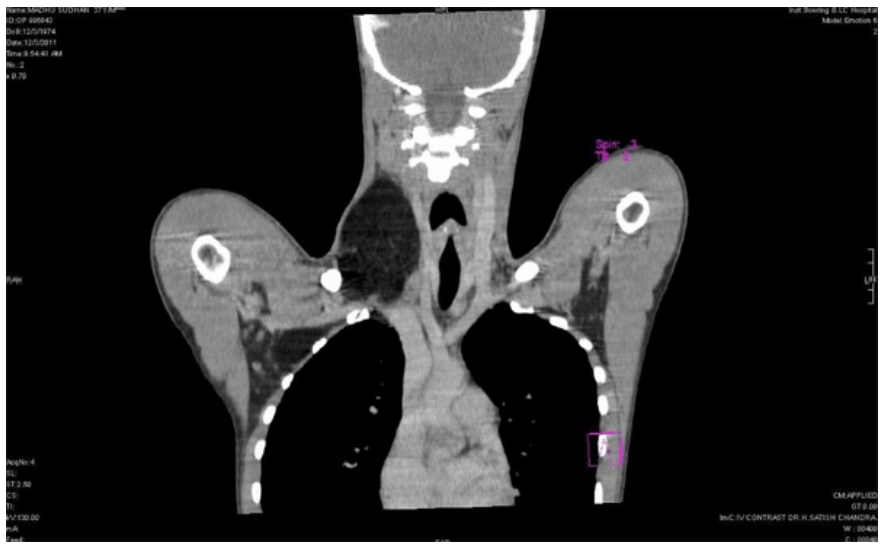

Figure 2: Computed tomography (CT) scan showing mediolateral extent of infiltrating lipoma.

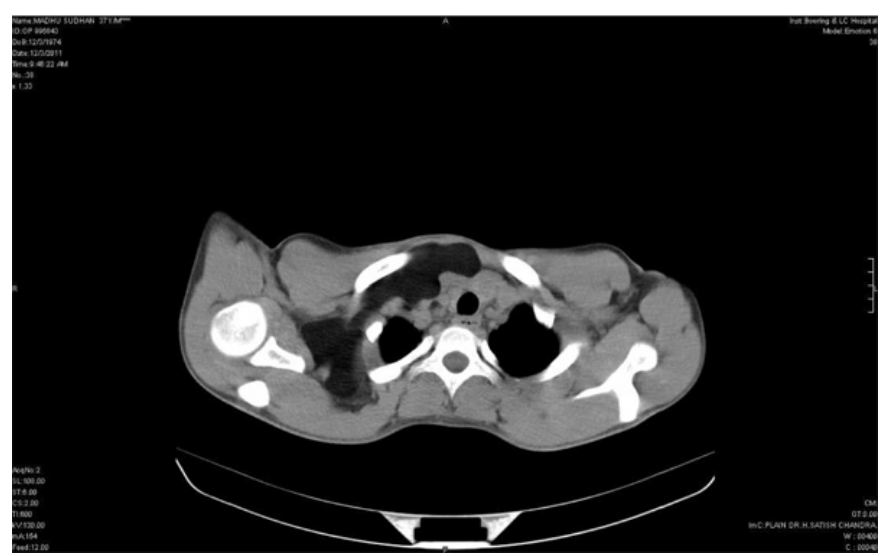

Figure 3: Computed tomography (CT) scan showing extent of infiltrating lipoma.

displacing subclavian vessels. Lesion had a uniform attenuation value between -40 to -140 Hounsfield units with minimal septations. A diagnosis of infiltrating lipoma was made and surgery was performed. The gross specimen was well encapsulated and histopathology features were consistant with lipoma. We presented this case because intermuscular lipomas of head and neck region are rare.

Descriptions of the sonographic appearance of lipomas are conflicting. Initially, lipomas were reported to be sonoluscent with a few internal echoes. Goldberg. described their internal echogenicity and poorly defined contours [6]. The reason for these conflicting reports may be due to the fact that most investigators group lipomas located in various parts of the body under one category such as those found in the extremities, thorax abdominal walls, kidneys, adrenals and pelvis [7]. With the availability of high-frequency, high-resolution transducers, the internal architecture and appearance of lipomas are now better understood. Head and neck lipomas are compressible, well defined, elliptical masses (88\%) parallel to the skin surface $(88 \%)$, are hyperechoic relative to adjacent muscle (76\%), contain linear echogenic lines at right angles to the ultrasound beam (100\%), and display no distal enhancement or attenuation (100\%) [8].

On CT scan, fat has low attenuation, less than -20 Hounsfield units and typically between -65 and -120 Hounsfield units [9]. Benign lipomas have a homogeneous low attenuation on CT scan. Malignant liposarcomas such as myxoid liposarcoma, account for $50 \%$ of all liposarcomas and demonstrate low to intermediate attenuation. They often have an inhomogeneous appearance owing to cystic areas representing myxoid material.

On CT scan, a lipoma is isodense with normal subcutaneous fat. The capsule may be barely visible or adjacent mass effect may be the only clue to its presence. Lipomas should not be confused with Madelung disease, also known as Launois-Bensaude disease, which occurs in middle-aged European men of Mediterranean descent with a history of alcohol abuse. In these patients, fat accumulates in the cervical and upper dorsal regions, abdomen and groin. The fatty deposits are of mixed echogenecity, with linear echogenic lines parallel to the skin surface and there is no evidence of a capsule.

Although sonography is able to depict the presence of fat in the soft tissues, it is unable to show the depth, extent of infiltration and airway compromise, if any. On CT scan lipomas have ane appearance of homogeneous lesion with low ionizing radiation attenuation values (o or negative values of Hounsield units) and a density lower than that of water. The accuracy rate of CT scan is 75-90\% for diagnosis of a lipoma.

Terzioglu et al. describe lipomas of $10.0 \times 5.0 \times 3.0 \mathrm{~cm}$ or greater as giant lipomas and note that tumors of this size should include liposarcomas in the differential diagnosis [5].

The classic magnetic resonance imaging (MRI) signal intensity for lipomas is similar to subcutaneous fat [8]. Therefore, on T1-weighted images, the lipomatous mass is isointense to surrounding subcutaneous fat. When fibrous connective tissue appears within the lipoma, the septa will show a decreased signal (hypointense) on all pulse sequences. Fat-suppressed T1-weighted images with contrast will demonstrate signal intensity suppression of the lipoma without enhancement of the lipoma or the septe.

Although liposarcomas resemble lipomas on both CT and MRI scans and both show MRI signal intensity that is equivalent to fat, the pathologic report in our case confirmed the absence of lipoblasts or significant atypical adipocytes. The presence of lipoblasts or atypical adipocytes would raise the concern for liposarcoma. Histologically, lipomas resemble normal fat, whereas well-differentiated liposarcomas, although resembling fat histologically also have dense bands of collagen traversing the mass with associated gelatinous areas.

Kransdorf et al. [10] reported that distinguishing between a well-differentiated liposarcoma and lipoma is challenging. Magnetic resonance imaging and CT scan depict well-differentiated liposarcomas as having thickened septe (defined as septe greater than $2 \mathrm{~mm}$ 
thick or focal thickening) and nodular and/or globular areas of non-adipose tissue within the lesion or associated with the mass. A lesion was considered entirely composed of adipose tissue if it demonstrated a signal intensity and character identical to that of the subcutaneous adipose tissue. The percentage of fat is graded from 0 to 4 as follows: $0=100 \%$ fat, $1=$ $90-99 \%$ fat, $2=75-90 \%$ fat, $3=50-75 \%$ fat, and $4=$ $50 \%$ fat or less. Non-adipose tissue comprising more than $25 \%$ of the lesion is also a feature consistent with well differentiated liposarcoma.

In summary, infiltrating or deep lipomas of head and neck are rare finding. Gaint lipomas in head and neck region have to be distinguished from liposarcoma. Surgical intervention of lipomas of neck are challenging because of the proximity of the blood vessels and nerve and thus the knowledge of anatomy and meticulous surgical technique are essential.

$* * * * * * * *$

Abhishek V, Patil V, Avinash V. Infiltrating lipoma of neck. International Journal of Case Reports and Images 2013;4(5):290-293.

$* * * * * * * * *$

doi:10.5348/ijcri-2013-05-315-LE-12

$* * * * * * * * *$

\section{Author Contributions}

Abhishek Vijayakumar - Substantial contributions to conception and design, Acquisition of data, Analysis and interpretation of data, Drafting the article, Revising it critically for important intellectual content, Final approval of the version to be published

Vijayraj Patil - Analysis and interpretation of data, Drafting the article, Revising it critically for important intellectual content, Final approval of the version to be published

Avinash Vijayakumar - Analysis and interpretation of data, Drafting the article, Revising it critically for important intellectual content, Final approval of the version to be published

\section{Guarantor}

The corresponding author is the guarantor of submission.

\section{Conflict of Interest}

Authors declare no conflict of interest.

\section{Copyright}

(C) Abhishek Vijayakumar et al. 2013; This article is distributed under the terms of Creative Commons Attribution 3.0 License which permits unrestricted use, distribution and reproduction in any means provided the original authors and original publisher are properly credited. (Please see www.ijcasereportsandimages.com /copyright-policy.php for more information.)

\section{REFERENCES}

1. Kransdorf MJ. Benign soft-tissue tumors in a large referral population: distribution of specific diagnoses by age, sex, and location. AJR Am J Roentgenol 1995;164(2):395-402.

2. El-Monem MH, Gaafar AH, Magdy EA. Lipomas of the head and neck: presentation variability and diagnostic work-up. J Laryngol Otol 2006;120(1):47-55.

3. Som PM, Scherl MP, Rao VM, Biller HF. Rare presentations of ordinary lipomas of the head and neck: a review. AJNR Am J Neuroradiol 1986;7(4):657-64.

4. Barnes L. Tumors and tumorlike lesions of the head and neck: In: Barnes L, ed. Surgical Pathology of the Head and Neck. New York, NY: Dekker 1985:747-58.

5. Terzioglu A, Tuncali D, Yuksel A, Bingul F, Aslan G. Giant lipomas: a series of 12 consecutive cases and a giant liposarcoma of the thigh. Dermatol Surg 2004;30(3):463-7.

6. Goldberg BB. Ultrasonic evaluation of superficial masses. J Clin Ultrasound 1975;3(2):91-4.

7. Gritzman N, Schratter M, Traxler M, Helmer M. Sonography and computed tomography in deep cervical lipomas and lipomatosis of the neck. J Ultrasound Med 1988;7(8):451-6.

8. Weissman JL. Nonnodal masses of the neck. In: Som PM, Curtin HD, eds. Head and Neck Imaging. 3rd ed. St Louis, MO: MosbyYear Book 1996:794-822.

9. Munk PL, Lee MJ, Janzen DL, et al. Lipoma and liposarcoma: evaluation using CT and MR imaging. AJR Am J Roentgenol 1997;169(2):589-94.

10. Kransdorf MJ, Bancroft LW, Peterson JJ, Murphey MD, Foster WC, Temple HT. Imaging of fatty tumors: distinction of lipoma and well-differentiated liposarcoma. Radiology 2002;224(1):99-104. 
Abhisher al. 293

Access full text article on

other devices

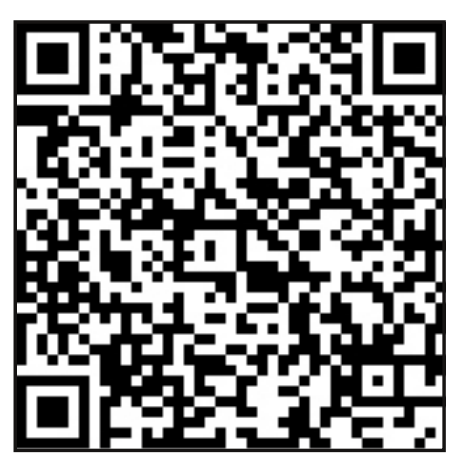

Access PDF of article on other devices

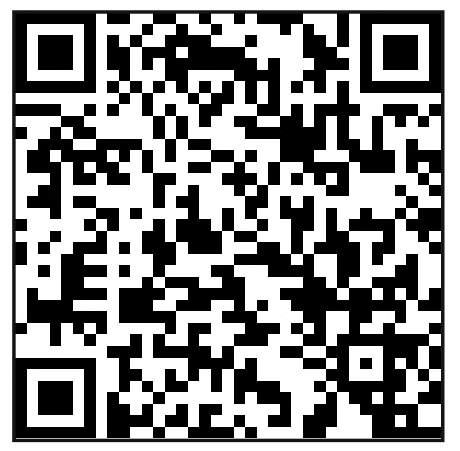

